Proc. Indian Acad. Sci. (Chem. Sci.), Vol. 89, Number 2, April 1980, pp. 101-108. (a) Printed in India.

\title{
Complexes of osmium with tertiary arsines and carbonmonoxide
}

\author{
K G SRINIVASAMURTHY, N M NANJE GOWDA, \\ E G LEELAMANI and $G K \mathbf{K}$ REDDY \\ Department of Chemistry, Central College, Bangalore University, Bangalore 560001 , \\ India
}

MS received 9 August 1979; revised 1 February 1980

\begin{abstract}
Osmium halides ( $\mathrm{Cl}$ and $\mathrm{Br}$ ) react with monotertiary arsines $\mathrm{Ph}_{2} \mathrm{RAs}$ $(\mathrm{R}=\mathrm{Me}, \mathrm{Et}, \mathrm{Pr}$ and Bu$)$ in alcoholic medium to give paramagnetic octahedral complexes of the type $\mathrm{OsX}_{\mathbf{3}} \mathrm{L}_{3}\left(\mathrm{X}=\mathrm{Cl}, \mathrm{Br} ; \mathrm{L}=\mathrm{Ph}_{2} \mathrm{RAs}\right)$ which further react with carbonmonoxide to give dihalo dicarbonyl complexes of osmium(II) of the type $\mathrm{OsX}_{2}(\mathrm{CO})_{2} \mathrm{~L}_{2}$. Similarly, osmium halides react with tertiary arsines in the presence of formaldehyde to give monocarbonyl complexes of osmium(II) of the type $\mathrm{OsX}_{2}(\mathrm{CO}) \mathrm{L}_{3}$. Structures have been assigned to all these compounds on the basis of IR and NMR studies.
\end{abstract}

Keywords. Osmium ; carbonmonoxide ; tertiary arsines ; IR spectra ; NMR spectra.

\section{Introduction}

Complexes of ruthenium and osmium stabilised by tertiary arsines have not been well investigated when compared to the corresponding compounds containing tertiary phosphines (Griffith 1967; McAuliffe 1973; Tripathi et al 1975; Reddy and Nanje Gowda 1977). Ruthenium and osmium are known to exhibit varied bohaviour while reacting with tertiary phosphines and arsines depending on the experimental conditions. We have reported recently some of our investigations on the reactions of ruthenium halides with tertiary arsines (Leelamani and Reddy 1975; Srinivasamurthy et al 1977). It has been shown that ruthenium trihalides react with carbonmonoxide and/or monotertiary arsines under appropriate experimental conditions to give six coordinate complexes of the type $\operatorname{RuX}_{3} \mathrm{~L}_{3}, \operatorname{RuX}_{2} \mathrm{~L}_{4}$, $\left[\mathrm{Ru}_{2} \mathrm{X}_{3} \mathrm{~L}_{\mathbf{6}}\right] \mathrm{X}, \mathrm{RuX}_{2}(\mathrm{CO})_{2} \mathrm{~L}_{2}$ and $\mathrm{RuX}_{2}(\mathrm{CO}) \mathrm{L}_{3}\left(\mathrm{X}=\mathrm{Cl}, \mathrm{Br} ; \mathrm{L}=\mathrm{Ph}_{2} \mathrm{MeAs}\right.$, $\left.\mathrm{Ph}_{2} \mathrm{EtAs}, \mathrm{Ph}_{2} \mathrm{PrAs}, \mathrm{Ph}_{2} \mathrm{BuAs}\right)$. It was, therefore, of interest to investigate the corresponding reactions involving osmium halides. These investigations are being reported here.

\section{Experimental}

Osmium salts $\left[\mathrm{Na}_{2} \mathrm{OsCl}_{6}\right.$ and $\left(\mathrm{NH}_{4}\right)_{2} \mathrm{OsBr}_{6}$ ] were supplied by Johnson Matthey Chemicals, London. The arsines $\mathrm{Ph}_{2} \mathrm{RAs}(\mathrm{R}=\mathrm{Me}, \mathrm{Et}, \mathrm{Pr}, \mathrm{Bu})$ were prepared 
by literature methods (Nanje Gowda 1975). IR (Nujol mulls), Far-IR (in polyethylene powder) and NMR (using $\mathrm{CDCl}_{3}$ as solvent and TMS as internal standard) spectra were recorded with Specord 75 IR, Polytec FIR 30 Fouricr spectrometer and Varian T-60 instruments, respectively. Microanalysis for carbon and hydrogen was carried out at the Universities of Sussex and Manchester, England. Halogen was estimated by sodium hydroxide fusion and subsequent titration by Volhard's method. The magnetic moment measurements were made at room temperature $\left(\sim 27^{\circ} \mathrm{C}\right)$ using a ' Gouly balance '.

2.1. Trihalotris (tertiary arsine) osmium(III) compounds: $O s X_{3}\left(P h_{2} R A s\right)_{3}$ $(X=C l, B r ; R=M e, E t, P r, B u)$

To a solution of sodium chloroosmate or ammonium bromoosmate $(0.1 \mathrm{mmol})$ in ethanol $(30 \mathrm{ml})$ containing hydrohalic acid $(0.5 \mathrm{ml})$, the arsine $(0.4 \mathrm{mmol})$ was added and the mixture was refluxed on a steam-bath for about $6 \mathrm{hr}$. The required compound separated as shining coloured crystals on cooling overnight. The compound was washed successively with water, alcohol and dried in vacuo.

\subsection{Cis-dihalodicarbonylbis (tertiary arsine) osmium(II) compounds:} $\mathrm{OsX}_{2}(\mathrm{CO})_{2}\left(\mathrm{Ph} \mathrm{h}_{2} \mathrm{RAs}\right)_{2}(X=\mathrm{Cl}, \mathrm{Br} ; \mathrm{R}=\mathrm{Me}, \mathrm{Et}, \mathrm{Pr}, \mathrm{Bu})$

(a) Carbonmonoxide was bubbled through a suspension of $\mathrm{OsX}_{3}\left(\mathrm{Ph}_{2} \mathrm{RAs}\right)_{8}$ $(0.1 \mathrm{mmol})$ in methoxyethanol $(30 \mathrm{ml})$ at refluxing temperature, till a colourless solution was obtained. To this solution dropwise addition of water produced the carbonyl complex as shining white crystals. The crystals were washed with water, alcohol and dried in vacuo.

(b) A solution of sodium chloroosmate or ammonium bromoosmate $(0.1 \mathrm{mmol})$ and the arsine $(0.3 \mathrm{mmol})$ in methoxyethanol was refluxed for $30 \mathrm{~min}$ and carbon monoxide was bubbled through the resulting solution (under reflux) till the reddish brown colour changed to yellow. The reaction mixture was concentrated under reduced pressure and cooled to room temperature when shining yellow crystals separated. The crystals were filtered, washed with alcohol and dried in vacuo.

\subsection{Trans-dihalodicarbonylbis (tertiary arsine) osmium(II) compounds :} $O s \mathrm{X}_{2}(\mathrm{CO})_{2}\left(\mathrm{Ph}_{2} R A s\right)_{2}(X=\mathrm{Cl}, \mathrm{Br} ; R=\mathrm{Me}, \mathrm{Et}, \mathrm{Pr})$

Carbonmonoxide was bubbled through a warm solution of $\mathrm{OsX}_{3}\left(\mathrm{Ph}_{2} \mathrm{RAs}\right)_{3}$ $(0.1 \mathrm{mmol})$ in acetone $(30 \mathrm{ml})$ in the presence of $\mathrm{Zn} / \mathrm{Hg}(0.3 \mathrm{~g})$ till a yellow solution was obtained. The solution was filtered and cooled in ice (or concentrated under reduced pressure) when yellow crystalline compound separated. The crystals were washed with alcohol and dried in vacuo.

\subsection{Dihalocarbonyltris (tertiary arsine) osmium(II) compounds; $\mathrm{OsX}_{2}(\mathrm{CO})\left(\mathrm{Ph}_{\mathbf{2}} \mathrm{RAs}\right)_{3}(X=\mathrm{Cl}, \mathrm{Br} ; \mathrm{R}=\mathrm{Me}, \mathrm{Et}, \mathrm{Pr})$}

A mixture of sodium chloroosmate or ammonium bromoosmate $(0.1 \mathrm{mmol})$, the tertiary arsine $(0.3 \mathrm{mmol})$ and aqueous formaldehyde $(5.0 \mathrm{ml} ; 37-41 \% \mathrm{w} / \mathrm{v})$ in methoxyethanol $(30 \mathrm{ml})$ was refluxed on a heating mantle for about $8 \mathrm{hr}$. Pale 
yellow or pink crystals separated on cooling overnight. The crystals were washed with water, alcohol and dried in vacuo.

\section{Results and discussion}

Sodium chloroosmate and ammonium bromoosmate react with the arsines $\mathrm{Ph}_{2} \mathrm{RAs}$ $(\mathrm{R}=\mathrm{Me}, \mathrm{Et}, \mathrm{Pr}, \mathrm{Bu})$ in the mole ratio $1: 4$ in alcoholic medium in presence of the corresponding hydrohalic acid to give non-ionic, paramagnetic complexes of the formula OsX $\mathrm{X}_{3} \mathrm{~L}_{3}\left(\mathrm{X}=\mathrm{Cl}, \mathrm{Br} ; \mathrm{L}=\mathrm{Ph}_{2} \mathrm{RAs}\right)$. The compound $\mathrm{OsCl}_{3}\left(\mathrm{Ph}_{2} \mathrm{MeAs}\right)_{3}$ has been reported earlier (Dwyer et al 1947). Attempts to prepare mononuclear and dinuclear halobridged complexes of osmium(II) of the formulae $\mathrm{OsX}_{2} \mathrm{~L}_{4}$ and $\left[\mathrm{Os}_{2} \mathrm{X}_{3} \mathrm{~L}_{6}\right] \mathrm{X}$ by using excess arsine (metal halido-arsine ratio of $1: 8$ ) as a reducing agent, as in the case of ruthenium halides were not successful. Similarly use of zinc-amalgam as a reducing agent also did not yield any osmium(II) compounds.

The observed magnetic moment values (table 1) of the trihalo compounds, $\mathrm{OsX}_{3} \mathrm{~L}_{3}$ are in the range expested for spin-paired octahedral complexes of osmium(III) (Chatt et al 1968; Figgis and Lewis 1964). Because of their paramagnetic nature the PMR spectra of these compounds are not useful for assigning their structures. Similarly the metal halogen frequencies in the far-IR region are masked by other ligand bands and cannot be located. A meridional structure I may be assigned to the complexes on the basis of analogous structures shown by the corresponding tertiary phosphine complexes (Chatt et al 1969).

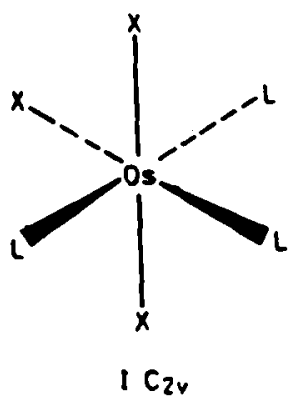

The trihalo complexes of osmium(III), $\operatorname{Os}_{8} \mathrm{~L}_{3}$ react with carbonmonoxide in refluxing methoxyethanol to give white crystalline complexes of osmium(II) of the type $\mathrm{OsX}_{2}(\mathrm{CO})_{2} \mathrm{~L}_{2}$. It is obvious that coordination of carbonmonoxide to the metal facilitates its reduction from +3 to +2 oxidation state. These dicarbonyl compounds are non-electrolytes in nitrobenzene and show two intense $v \mathrm{CO}$ peaks around $2000 \mathrm{~cm}^{-1}$ in the infrared (table 2) suggesting that the two carbonyls are located cis to each other. The proton NMR spectra of the compounds $\operatorname{OsX}_{2}(\mathrm{CO})_{2} \mathrm{~L}_{2}$ $\left(\mathrm{X}=\mathrm{Cl}, \mathrm{Br} ; \mathrm{L}=\mathrm{Ph}_{2} \mathrm{MeAs}, \mathrm{Ph}_{2} \mathrm{EtAs}\right.$ ) exhibit a single methyl or ethyl resonance pattern (table 2) due to the methyl or ethyl protons of the coordinated arsine ligands, indicating that the two arsines in each of the compounds are located in identical environments. Hence, these dicarbonyl compounds should have one of the two structures, II or III. On steric considerations it is likely that location of two 


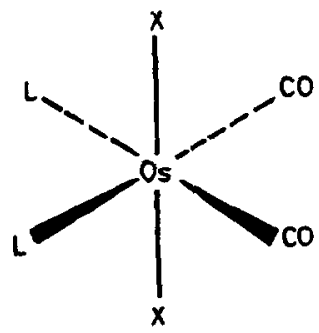

II $\mathrm{C}_{2 v}$

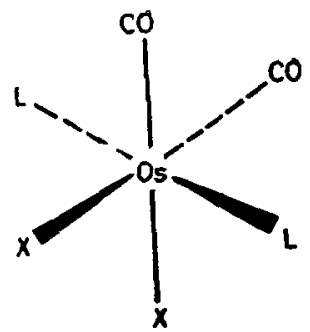

III $C_{2 v}$

Table 1. Physical properties and analytical data of Os(III) complexes.

\begin{tabular}{|c|c|c|c|c|c|c|}
\hline \multirow{2}{*}{ Compound } & \multirow{2}{*}{ Colour } & \multirow{2}{*}{ M.P. $\left({ }^{\circ} \mathrm{C}\right)$} & \multirow{2}{*}{$\begin{array}{l}\mu_{\text {off }}^{b} \\
(\mathrm{BM})\end{array}$} & \multicolumn{3}{|c|}{ Analytical data $\left.C^{\circ}\right)^{\circ}$} \\
\hline & & & & C & $\boldsymbol{H}$ & $\boldsymbol{x}$ \\
\hline $\mathrm{OsCl}_{3}\left(\mathrm{Ph}_{2} \mathrm{MeAs}\right)_{3}$ & Brick red & $175-77$ & $1 \cdot 980$ & $45 \cdot 4(45 \cdot 5)$ & $3.9(3 \cdot 8)$ & $9.5(10 \cdot 4)$ \\
\hline $\mathrm{OsBr}_{2}\left(\mathrm{Ph}_{2} \mathrm{MeAs}\right)_{2}$ & Dark violet & $197-201$ & 1.943 & $40.5(40 \cdot 2)$ & $3 \cdot 8(3 \cdot 4)$ & $20 \cdot 2(20 \cdot 6)$ \\
\hline $\mathrm{OsCl}_{3}\left(\mathrm{Ph}_{2} \mathrm{EtAs}_{3}\right.$ & Brick red & $187-90$ & 1.998 & $47 \cdot 3(47 \cdot 1)$ & $4 \cdot 3(4 \cdot 2)$ & $9.2(9.9)$ \\
\hline $\mathrm{OsBr}_{3}\left(\mathrm{Ph}_{2} \mathrm{EtAs}\right)_{2}$ & Dark violet & 189_92 & 1.943 & $41 \cdot 3(41 \cdot 9)$ & $3 \cdot 8(3 \cdot 7)$ & $18.9(19.9)$ \\
\hline $\mathrm{OSCl}_{3}\left(\mathrm{Ph}_{2} \mathrm{PrAs}\right)_{3}$ & Orange red & $208-10$ & NM & $48 \cdot 6(48 \cdot 5)$ & $4 \cdot 9(4 \cdot 6)$ & $8.7(9.6)$ \\
\hline $\mathrm{OsBr}_{4}\left(\mathrm{Ph}_{2} \mathrm{PrAs}_{3}\right.$ & Reddish brown & $184-88$ & $\mathbf{N M}$ & $43 \cdot 3(43 \cdot 3)$ & $4 \cdot 0(4 \cdot 1)$ & $18 \cdot 7(19 \cdot 2)$ \\
\hline $\mathrm{OsCl}_{3}\left(\mathrm{Ph}_{8} \mathrm{BuAs}\right)_{3}$ & Orange red & $166-68$ & NM & $50 \cdot 4(49 \cdot 8)$ & $5 \cdot 5(4.9)$ & $8.9(9.2)$ \\
\hline $\mathrm{OsBr}_{2}\left(\mathrm{Ph}_{2} \mathrm{BuAs}\right)_{3}$ & Reddish brown & $181-83$ & NM & $44 \cdot 5(44 \cdot 7)$ & $4 \cdot 9(4 \cdot 4)$ & $18 \cdot 1(18 \cdot 6)$ \\
\hline
\end{tabular}

- Calculated values are in parentheses. ${ }^{b}$ Magnetic moment values were measured at room temperature.

$\mathrm{NM}=$ not measured.

bulky arsines in cis positions would be less favourable and hence during substitution the arsine that gets replaced from complexes of structure I would be the one that is trans to a halogen. This way it is likely that the resulting complex would have structure III rather than II. As a supporting evidence the far-IR spectra of $\mathrm{OsX}_{2}(\mathrm{CO})_{2}\left(\mathrm{Ph}_{2} \mathrm{EtAs}\right)_{2}$ show two intense bands due to vOs-Cl $\left(281,307 \mathrm{~cm}^{-1}\right)$ or $\nu O s-\mathrm{Br}\left(192,211 \mathrm{~cm}^{-1}\right)$ which suggests cis location of halide groups. Similar observations have been made earlier in these laboratories with respect to nucleophilic substitution reactions involving complexes of rhodium of the type $\operatorname{RhX}_{3} \mathbf{L}_{3}$ (Nanje Gowda and Reddy 1974; Srinivasamurthy et al 1979) having structure I. It may also be noted that Chatt et al (1971) have assigned structure III for similar complexes of osmium with tertiary phosphines. We have also observed that bubbling of carbon monoxide through a methoxyethanol solution of osmium salt and arsino $\left(\mathrm{Ph}_{2} \mathrm{RAs}\right)$ in the ratio $1: 3$ at refluxing temperature yields yellow crystalline products whose IR and NMR spectral results coincide with those of the above cis-dicarbonyls. There is, however, some difference in the colours of the dicarbonyls propared by the two different routes. It is likely that this is due to difference 


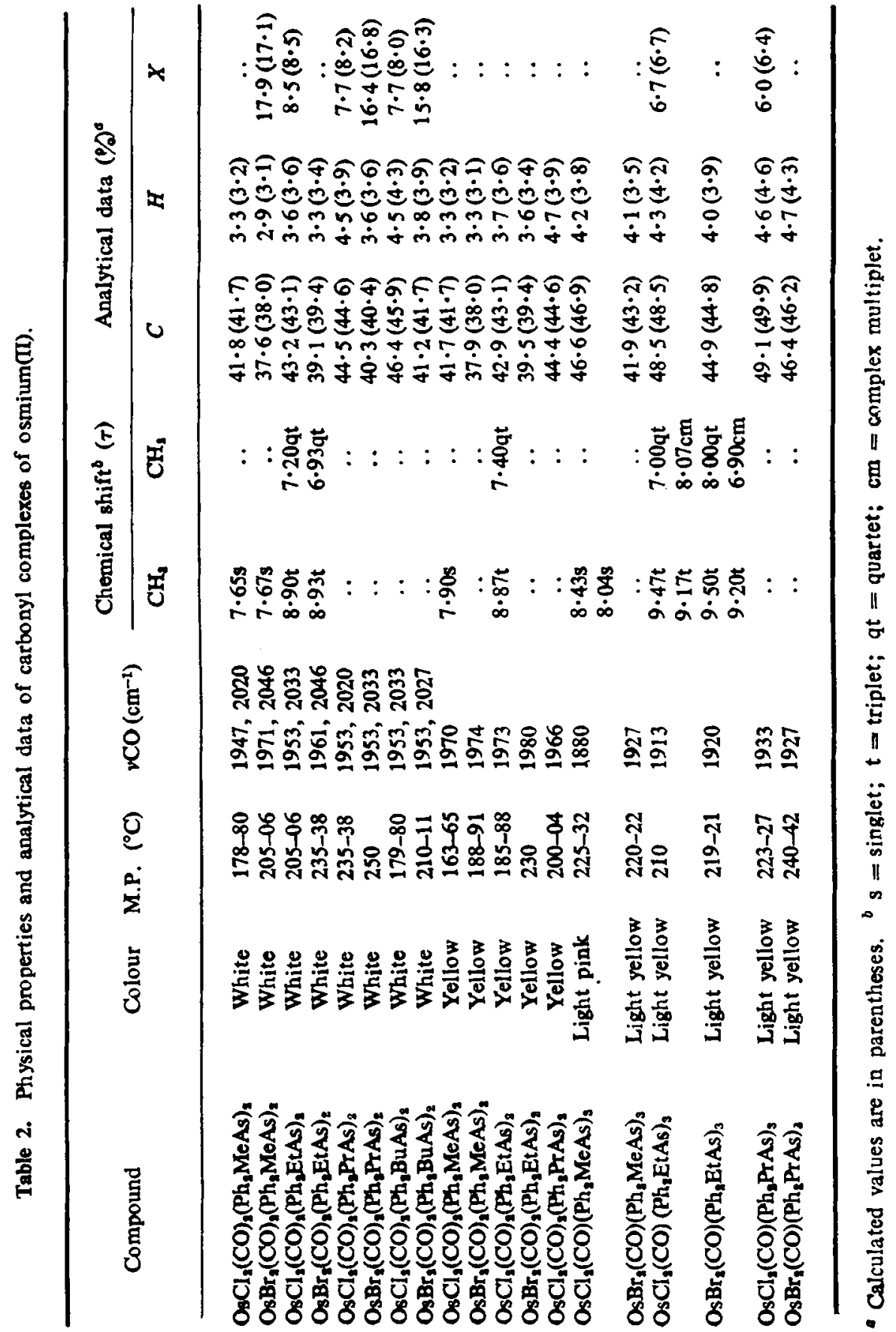


in crystal packing rather than to difference in stereochemistry. The various reactions that have been carried out are shown in scheme 1 .

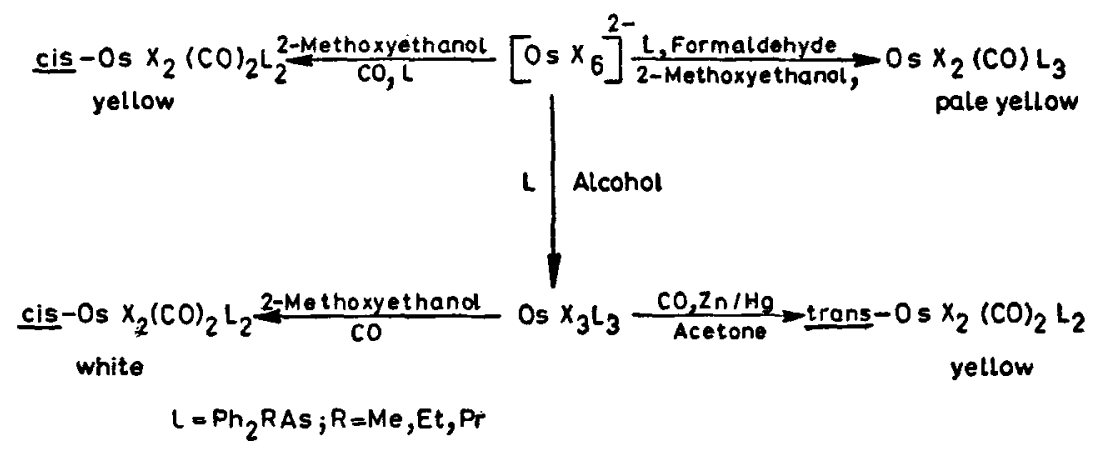

Scheme 1

When carbonmonoxide is passed through solutions of the trihalo compounds $\mathrm{OsX}_{3} \mathrm{~L}_{2}\left(\mathrm{~L}=\mathrm{Ph}_{\mathbf{2}} \mathrm{RAs} ; \mathrm{R}=\mathrm{Me}, \mathrm{Et}, \mathrm{Pr}\right)$ in warm acetone in the presence of zinc-amalgam, yellow crystalline products which should also be formulated as OsX $\mathrm{X}_{2}\left(\mathrm{CO}_{2}\right) \mathrm{L}_{2}$ are obtained. These again give non-conducting solutions in nitrobenzene but show a single $\nu \mathrm{CO}$ peak around $2,000 \mathrm{~cm}^{-1}$ (table 2) in the infrared suggesting a trans disposition of the two carbonyl groups. The PMR spectra of these compounds $(R=\mathrm{Me}, \mathrm{Et})$ show a single methyl or ethyl resonance pattern due to the coordinated arsines, which means that the arsines are located in an identical environment in each of the above compounds. The above results suggest that the dicarbonyls should have structure IV or V. Based on factors cited earlier

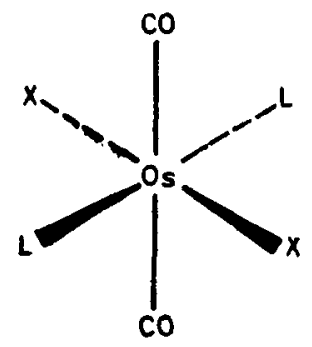

IV $D_{2 v}$

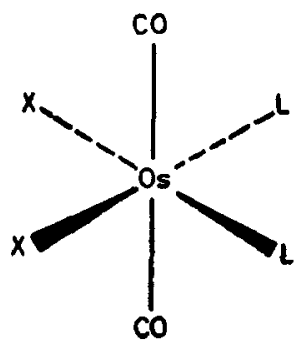

$v \mathrm{C}_{2 v}$

it is likely that the centrosymmetric structure IV would be more favourable than structure $\mathrm{V}$ for these compounds. Further, the far-IR spectra of the compounds $\mathrm{OsX}_{2}(\mathrm{CO})_{2}\left(\mathrm{Ph}_{2} \mathrm{EtAs}\right)_{2}(\mathrm{X}=\mathrm{Cl}, \mathrm{Br})$ have been taken and these show a single vOs-X band ( $\mathrm{Os}-\mathrm{Cl}=316, \nu \mathrm{Os}-\mathrm{Br}=235 \mathrm{~cm}^{-1}$ ) supporting the assignment of structure IV for the above dicarbonyls. It is also found that when these trans dicarbonyls (configuration IV) are refluxed in methoxyethanol solvent they are converted to the more stable cis dicarbonyls of configuration III. Similar observations have been made by earlier workers with analogous complexes of ruthenium and osmium (Barnard et al 1976; Chatt et al 1971; James and Markham 1971). 
Robinson and coworkers (Ahmed et al 1972) have found that the use of formaldehyde in a reaction involving sodium hexachloroosmate and triphenyl phosphine in methoxy-ethanol results in the formation of a hydridocarbonyl, OsHCl(CO) $\left(\mathrm{Ph}_{3} \mathrm{P}_{3}\right.$. Our attempts to isolate hydridocarbonyls under similar conditions using tertiary arsines resulted in the formation of non-ionic, monocarbonyl compounds of the formula $\mathrm{OsX}_{2}(\mathrm{CO}) \mathrm{L}_{3}$. These compounds show a carbonyl stretching band around $1900 \mathrm{~cm}^{-1}$ in the infrared and their PMR spectra $(R=M e, \mathrm{Et})$ possess two methyl or ethyl resonance patterns (table 2) of relative intensity $2: 1$ indicating that two of the three arsines are trans to each other. The monocarbonyl compounds should therefore have either of the two structures, VI or VIII (M $=$ Os;

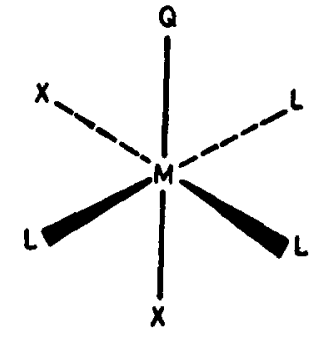

vi $\mathrm{C}_{\mathrm{s}}$

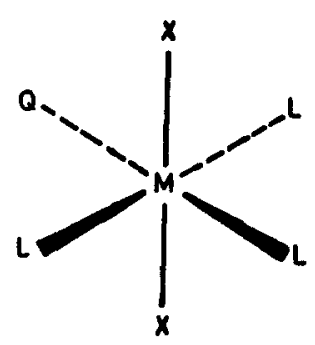

vil $c_{2 v}$

$\mathrm{L}=\mathrm{Ph}_{2} \mathrm{RAs} ; \mathrm{Q}=\mathrm{CO}$ ). It has been shown earlier that in the NMR spectra of complexes with structure VI $\left(M=I r ; \quad Q=H ; \quad L=P_{2}\right.$ EtAs) (Reddy and Leelamani 1973) the quartet due to methylene protons of the trans arsines is split due to the lower symmetry of the molecule, while the corresponding quartet of the methylene protons in the spectra of complexes with structure VII do not show any splitting. Examination of the PMR spectra of these complexes $(M=O s$; $\mathrm{Q}=\mathrm{CO} ; \mathrm{L}=\mathrm{Ph}_{2} \mathrm{EtAs}$ ) reveals that the methylene proton resonances of the trans arsines are indeed split indicating that the compounds have structure VI.

\section{Acknowledgements}

The authors are indebted to Professor J Chatt and Dr D J Machin, England, for microanalysis. The authors are also thankful to Professor $S$ Chandrasekhar and Dr S Venugopal, Raman Research Institute, Bangalore, for far-IR spectra and the authorities of Indian Institute of Science, for NMR spectra. One of the authors (KGS) is grateful to the University Grants Commission, New Delhi, for financial assistance (F.I.P).

\section{References}

Ahmed N, Robinson S D and Uttley M F 1972 J. Chem. Soc. (Dalton) p. 843

Barnard C F J, Daniels J A, Jeffery J and Mawby R J 1976 J. Chem. Soc. (Dalton) p. 953

Chatt J, Melville D P and Richards R L $1971 \mathrm{~J}$. Chem. Soc. $(A) 1169$

Chatt J, Leigh G J and Mingos D M P 1969 J. Chem. Soc. (A) p. 1674 
Chatt J, Leigh G J, Mingos D M P and Paske R J 1968 J. Chem. Soc. (A) p. 263

Dwyer F P, Nyholm R S and Tyson B T 1947 J. Proc. R. Soc. NS Wales 81272

Figgis B N and Lewis J 1964 Prog. Inorg. Chem. 6175

Griffith W P 1967 The chemistry of rarer platinum metals (New York: Interscience)

James B R and Markham L D 1971 Inorg. Nucl. Chem. Lett. 7373

Leelamani E G and Reddy G K N 1975 Inorg. Nucl. Chem. Lett. 115

McAuliffe C A 1973 Transition metal complexes of phosphorus, arsenic and antimony ligands (London: Macmillan)

Nanje Gowda N M 1975 Some tertiary arsine and phosphine complexes of platinum group metals, Ph.D. Thesis, Bangalore University

Nanje Gowda N M and Reddy G K N 1974 J. Inorg. Nucl. Chem. 363745

Nanje Gowda N M and Reddy G K N 1975 Indian J. Chem. 131064

Reddy G K N and Leelamani E G 1973 Indian J. Chem. 11169

Reddy G K N and Nanje Gowda N M 1977 J. Indian Chem. Soc. 54289

Srinivasamurthy K G, Nanje Gowda N M and Reddy G K N 1977 J. Inorg. Nucl. Chem. 39 1977

Srinivasamurthy K G, Nanje Gowda N M and Reddy G K N 1979 Indian J. Chem. A18 322

Tripathi S C, Srivastava S C, Mani R P and Shrimal A K 1975 Inorg. Chim. Acta 15249 